\title{
EDUCAÇÃO EM SAÚDE DA MULHER: EXPERIÊNCIA NA ESTRATÉGIA SAÚDE DA FAMÍLIA
}

\author{
Victor André Maia Fernandes'; Álvaro Rafael do Nascimento Elias Macêdo'; Beatriz \\ Albuquerque Bomfim'; Janaína Santos da Silva1; Lucas Fretes Alves; Lucas Iannuzzi \\ Martins'; Tayenne Figueiredo Bentes $^{1}$ \\ ${ }^{1}$ Acadêmico de medicina. Universidade do Estado do Amazonas (UEA), Manaus, Amazonas.
}

DOI: 10.47094/IICNNESP.2021/163

\section{RESUMO}

Introdução: Políticas como a de prevenção ao câncer de colo de útero são fundamentais na Atenção Primária à Saúde e a visita domiciliar possui importante papel no contato e na inclusão de pessoas no sistema de saúde. Objetivo: Dialogar com as mulheres da região em visitas domiciliares a fim de perceber o nível de conhecimento, elucidar suas dúvidas e entender suas críticas a respeito da prevenção do câncer de colo de útero. Metodologia: Trata-se um relato de experiência em que utilizamos de abordagem qualitativa e transversal através de visitas domiciliares sob supervisão. Discussão: A maioria das mulheres da região possuía bom grau de conhecimento a respeito da periodicidade do exame preventivo, porém algumas não o realizavam por terem sido desrespeitadas em oportunidades anteriores. Considerações finais: A visita domiciliar estabelece um canal de diálogo mais simples com a população e permitiu entender as dúvidas e os temores das mulheres a respeito do exame.

PALAVRAS-CHAVE: Visita domiciliar. Câncer de colo de útero. Prevenção.

ÁREA TEMÁTICA: Educação em Saúde.

\section{INTRODUÇÃO}

A visita domiciliar possui papel "importante para a construção de novas relações entre profissionais e familiares, formação de vínculos, aumento do acesso a serviços de saúde, maior acesso às informações sobre os serviços disponíveis e melhor compreensão das necessidades e dos contextos das famílias acompanhadas" (Nunes CA et al, 2018) isto é, busca-se o problema na sua base e empodera-se o indivíduo com conhecimento a respeito de sua própria saúde, servindo como uma ferramenta importante de inclusão de pessoas no sistema de saúde, assim como uma forma eficaz e de excelente custo-benefício no combate a comorbidades comuns na comunidade. Políticas como a de prevenção ao câncer de colo de útero, principalmente no Estado do Amazonas, onde a incidência e mortalidade ultrapassam os níveis nacionais, são fundamentais nesse nível de atenção.

\section{METODOLOGIA}

Trata-se um relato de experiência em que utilizamos de abordagem qualitativa e transversal na área de atuação da UBSF-O 02, no Bairro da Paz, em Manaus, Amazonas, através de visitas domiciliares sob supervisão de agentes comunitários de saúde. 
Um roteiro semiestruturado foi construído para estabelecer uma comunicação simples e precisa, fornecer espaço para diálogo atrelado a orientações e compreender o nível de informação a respeito das medidas de prevenção ao câncer de colo de útero.

Para todas as mulheres foram abordados os seguintes temas no contexto de uma conversa: A função do exame preventivo, a partir de que idade deve ser realizado e qual a sua periodicidade. Após as visitas foram feitas discussões entre os autores e os profissionais da UBS. Neste momento discutiu-se a respeito de vulnerabilidades em comum em cada visita domiciliar e identificamos relatos parecidos com o objetivo de reconhecer situações que se repetem na comunidade.

\section{RESULTADOS E DISCUSSÕES}

Foi observado que a maioria das mulheres possuía certo grau de conhecimento a respeito do exame preventivo tanto a cerca de sua finalidade com também de sua periodicidade. Entretanto, a grande maioria relatou que acreditava que o exame preventivo se tratava de um exame ginecológico básico, que poderia diagnosticar diversas outras patologias, principalmente DSTs.

Quando questionadas a respeito da periodicidade do exame e a partir de quando se deve iniciálo, percebeu-se que as mulheres eram informadas de que o exame deveria ser anual, porém em sua grande maioria não sabiam quando deveriam começá-lo. Algumas mulheres estavam há mais de 3 anos sem realizar o exame preventivo. Quando interrogadas sobre o porquê, algumas citaram a dificuldade de conseguir atendimento com ginecologistas, acreditando que tal exame não poderia ser realizado por outros profissionais. Nesse caso, esclarecemos que o exame preventivo não é apenas atribuição de profissionais ginecologistas e as convidamos para realizá-lo na UBS da região.

Outras usuárias relataram terem se sentido desrespeitadas por profissionais durante a procura pelo exame ou ainda que não se sentiam confortáveis em realizar o procedimento com profissionais do sexo masculino, mesmo acompanhadas.

A visita domiciliar proporcionou a oportunidade de conhecer um pouco da realidade de cada uma das mulheres e entender as dificuldades que limitam a procura ao serviço de saúde para a realização do exame preventivo, apesar do conhecimento que tais mulheres demonstraram a respeito de sua própria saúde.

\section{CONSIDERAÇÕES FINAIS}

A visita domiciliar estabeleceu um canal direto entre a UBS e a comunidade, permitindo entender e elucidar as dúvidas e compreender as críticas das usuárias ao atendimento para, por fim, melhorar o acolhimento e integrar a unidade de saúde à região e aos moradores.

Além disso, é importante ressaltar como a boa relação médico-paciente é imprescindível, especialmente em casos como esses, que pode ter um grande impacto na qualidade de vida da mulher, ao deixar de realizar o exame preventivo, possuindo íntima relação com o prognóstico dessa doença. 


\section{PRINCIPAIS REFERÊNCIA}

NUNES, Cristiane Abdon et al. Visitas domiciliares no Brasil: características da atividade basilar dos Agentes Comunitários de Saúde. Saúde debate, Rio de Janeiro, v. 42, n. spe2, p. 127-144, Oct. 2018.

LOPES, W. O. et. al. Visita domiciliar: tecnologia para o cuidado, o ensino e a pesquisa - DOI: 10.4025/cienccuidsaude.v7i2.5012. Ciência, Cuidado e Saúde, v. 7, n. 2, p. 241-247, 11 set. 2008.

Diretrizes brasileiras para o rastreamento do câncer do colo do útero / Instituto Nacional de Câncer José Alencar Gomes da Silva. Coordenação de Prevenção e Vigilância. Divisão de Detecção Precoce e Apoio à Organização de Rede. - 2. ed. rev. atual. - Rio de Janeiro: INCA, 2016.

Instituto Nacional de Câncer José Alencar Gomes da Silva. INCA. Amazonas e Manaus - Estimativa 2020. Disponível em < https://www.inca.gov.br/estimativa/estado-capital/amazonas-manaus. 